\title{
Gastrointestinal Bleeding and Direct Oral Anticoagulants among Patients with Atrial Fibrillation: Risk, Prevention, Management, and Quality of Life
}

\author{
Paolo Zappulla ${ }^{1}$ Valeria Calvi ${ }^{1}$ \\ ${ }^{1}$ Division of Cardiology, Centro alte specialità e trapianti (C.A.S.T.), \\ Azienda Ospedaliero-Universitaria Policlinico "G. Rodolico - \\ San Marco," University of Catania, Catania, Italy \\ TH Open 2021;5:e200-e210.
}

\begin{abstract}
Address for correspondence Paolo Zappulla, MD, C.A.S.T, Azienda Ospedaliero-Universitaria Policlinico (G. Rodolico - San Marco), Università di Catania, Via Santa Sofia 78, 95123, Catania, Italy (e-mail: paolozappulla88@gmail.com).
\end{abstract}

Abstract
Keywords
- oral anticoagulant
- gastrointestinal
bleeding
- warfarin
- rivaroxaban
- dabigatran
- edoxaban
- apixaban

A significant problem for patients undergoing oral anticoagulation therapy is gastrointestinal bleeding (GIB), a problem that has become increasingly urgent following the introduction of direct oral anticoagulants (DOACs). Furthermore, in recent years a greater focus has been placed on the quality of life $(\mathrm{QOL})$ of patients on long-term oral anticoagulant therapy, which necessitates changes in lifestyle, as well as posing an increased risk of bleeding without producing objective symptomatic relief. Here, we examine current evidence linked to GIB associated with oral anticoagulants, with a focus on randomized control trials, meta-analyses, and postmarketing observational studies. Rivaroxaban and dabigatran (especially the 150-mg bis-in-die dose) appeared to be linked to an increased risk of GIB. The risk of GIB was also greater when edoxaban was used, although this was dependent on the dose. Apixaban did not pose a higher risk of GIB in comparison with warfarin. We provided a summary of current knowledge regarding GIB risk factors for individual anticoagulants, prevention strategies that lower the risk of GIB and management of DOAC therapy after a GIB episode.

\section{Introduction}

Novel direct oral anticoagulants (DOACs) have proven to work effectively in preventing and treating thrombosis. Therefore, they now represent the primary therapeutic drugs in the prevention of both venous thromboembolism (VTE) and ischemic stroke in atrial fibrillation (AF). ${ }^{1}$ The guidelines published by the European Society of Cardiology (ESC) regarding the management of AF contain a class-IA recommendation, that, DOACs are recommended as the drug of choice for preventing AF in place of warfarin. ${ }^{2}$ In comparison to warfarin, DOACs have shown rapid onset and offset of action, predictable pharmacodynamics thus eliminating the need for regular therapeutic monitoring, and fewer food-drug or drug-drug interactions. $^{3}$ While multiple meta-analyses and phase-IV

received

February 11, 2021

accepted after revision

April 9, 2021 studies have demonstrated that DOACs have a favorable safety profile, high-risk patients are still at risk of bleeding, particularly gastrointestinal bleeding (GIB). Several studies have shed light on how GIB is determined by the DOAC regimen. ${ }^{4,5}$ Patient quality of life (QOL) can be affected during treatment with an oral anticoagulant, since it may necessitate lifestyle changes and increase risk of bleeding without providing objective symptom relief. Better treatment adherence is linked to greater satisfaction regarding anticoagulant treatment, and thus to an improved QOL.,7 Health-related QOL (HRQOL) is usually assessed by questionnaires that evaluate patients globally, not considering their diagnosis, such as Short Form (SF) 36 or the World Health Organization (WHO) QOL-BREF. ${ }^{8-13}$ Here, we summarized the evidence currently available with regard to GIB in the context of DOAC treatment used to lower the risk of

\section{(c) 2021. The Author(s).}

This is an open access article published by Thieme under the terms of the Creative Commons Attribution License, permitting unrestricted use, distribution, and reproduction so long as the original work is properly cited. (https://creativecommons.org/licenses/by/4.0/) Georg Thieme Verlag KG, Rüdigerstraße 14, 70469 Stuttgart, Germany 
stroke and systemic embolus in AF. This was performed via a PubMed search using the terms "gastrointestinal bleeding and anticoagulants," and gathering evidence restricted to the past 7 years, as well as previously published references that were deemed significant. All material was subsequently screened and the reports considered most relevant were selected, including meta-analysis or systematic reviews of randomized clinical trials (RCTs) in first place. After these came, singleclinical trials, meta-analysis of observational studies, or quality single observational studies featured a sample size greater than 100 observations. The main source of information was provided by RCTs of anticoagulation in patients with AF.

\section{Risk of Gastrointestinal Bleeding with Direct Oral Anticoagulants}

\section{Pharmacology of Direct Oral Anticoagulants}

The anticoagulation effects of DOACs are exerted by targeting single enzymes. Apixaban, edoxaban, and rivaroxaban are inhibitors of factor Xa, while thrombin is inhibited directly by dabigatran. These characteristics allow for the administration of a predictable dose without the need for plasma monitoring of coagulation factors. Dabigatran etexilate is a prodrug that, following oral administration, is converted to its active form, where it then functions as a reversible and competitive direct thrombin inhibitor. Multiple doses in healthy volunteers show the drug to have a half-life of 12 to 14 hours, although in patients whose creatinine clearance $(\mathrm{CrCl})$ is less than $30 \mathrm{~mL} / \mathrm{min}$, this increases to more than 24 hours. It was noted that $80 \%$ of dabigatran is eliminated by renal excretion. It can be taken at a dose of $150-\mathrm{mg}$ bis in die (b.i.d.). However, this should be lowered to $110-\mathrm{mg}$ b.i.d. in cases of renal deficiency, along with $\mathrm{CrCl}<50 \mathrm{~mL} / \mathrm{min}$.

Dabigatran is instead contraindicated in the presence of severe renal impairment, $\mathrm{CrCl}<30 \mathrm{~mL} / \mathrm{min}$ or in cases of advanced liver disease. ${ }^{1,14}$ Rivaroxaban functions as an oxazolidinone-derived anticoagulant that inactivates factor Xa. As a result, the intrinsic and extrinsic pathways of the blood coagu- lation cascade are interrupted. Following oral administration, plasma concentration reaches its maximum after 1 to 4 hours. While the effects last approximately 12 hours, factor Xa activity requires more than 24 hours to return to normal levels, so it can therefore be taken once a day. Elimination is $50 \%$ hepatobiliary and $35 \%$ renal, therefore patients with $\mathrm{CrCl} \leq 15 \mathrm{~mL} / \mathrm{min}$ or child class-B or -C liver disease should not be administered rivaroxaban. ${ }^{1,15}$ It is given at a dose of $20 \mathrm{mg}$ daily, or $15 \mathrm{mg}$ daily if $\mathrm{CrCl}$ is $<50 \mathrm{~mL} / \mathrm{min}$. One other oral selective inhibitor of factor Xa is apixaban, $30 \%$ of the drug is eliminated via renal excretion with a half-life of approximately 5 hours. The kidneys excrete $25 \%$ of the absorbed drug, with a half-life of approximately 12 hour. Apixaban is taken at a dose of $5-\mathrm{mg}$ b.i.d., although this should be lowered to $2.5 \mathrm{mg}$ if patients fall into two or more of the following categories: aged 80 years or over, body weight $60 \mathrm{~kg}$ or less, or serum creatinine $1.5 \mathrm{mg} / \mathrm{dL}$ or more. ${ }^{1,5}$ An oral direct inhibitor of factor Xa that resembles both rivaroxaban and apixaban is edoxaban. It reaches maximum serum concentrations within 1 hour to 2 hours and is characterized by $50 \%$ renal excretion of $60 \mathrm{mg}$ daily. However, this goes down to $30 \mathrm{mg}$ daily if the patient presents $\mathrm{CrCl}<50 \mathrm{~mL} / \mathrm{min}$ or weighs less than $60 \mathrm{~kg}$. Edoxaban is contraindicated in patients with severe renal impairment $(\mathrm{CrCl}<15 \mathrm{~mL} / \mathrm{min})$ and advanced liver disease. ${ }^{5,16}$ The characteristics of different DOACs are summarized in - Table 1.

\section{Risk of Direct Oral Anticoagulants-Related} Gastrointestinal Bleeding in Randomized Clinical Trials The efficacy and safety of DOACs have been studied in several clinical trials and risk of GIB depends on the DOAC regimen. The four landmark phase-III RCTs are summarized in - Table 2.

RE-LY was an RCT in which warfarin was compared with dabigatran at twice-daily doses of 110 and $150 \mathrm{mg}$, respectively. ${ }^{17}$ In comparison with warfarin and dabigatran administered at a dose of $110 \mathrm{mg}$, dabigatran $150 \mathrm{mg}$ twice daily was linked to an increased prevalence of GIB (hazard ratio [HR]: $1.48 ; 95 \%$ confidence interval [CI]: 1.18-1.85 and HR: 1.36; 95\% CI: 1.09-1.70, respectively). However, incidences

Table 1 Characteristics of different novel oral anticoagulants

\begin{tabular}{|c|c|c|c|c|}
\hline Characteristics & Dabigatran & Rivaroxaban & Edoxaban & Apixaban \\
\hline Mechanism of action & Antithrombin & Antifactor Xa & Antifactor Xa & Anti-factor Xa \\
\hline Bioavailability & $3-7 \%$ & $\begin{array}{l}66 \% \text { without food, } \\
80-100 \% \text { with food }\end{array}$ & $50 \%$ & $62 \%$ \\
\hline Tmax (h) & 1.5 & 2.5 & 3 & $1-5$ \\
\hline T $1 / 2(h)$ & $12-17$ & $\begin{array}{l}5-9 \text { (young) } \\
11-13 \text { (elderly) }\end{array}$ & 12 & $10-14$ \\
\hline Dosing & b.i.d & Once daily & b.i.d & Once daily \\
\hline $\begin{array}{l}\text { Clearance non renal } \\
\text { (\%)/renal of absorbed dose (\%) }\end{array}$ & $20 / 80$ & $65 / 35$ & $73 / 27$ & $50 / 50$ \\
\hline $\begin{array}{l}\text { Liver metabolism: } \\
\text { CYp3A4 involved }\end{array}$ & No & $18 \%$ & $25 \%$ & $<4 \%$ \\
\hline Absorption with food & No effect & $\begin{array}{l}+35 \% \text { more (therefore needs } \\
\text { to be taken with food) }\end{array}$ & No effect & $\begin{array}{l}6-22 \% \text { more; minimal } \\
\text { effect on exposure }\end{array}$ \\
\hline
\end{tabular}

Abbreviations: b.i.d., bis in die; Tmax, time to peak plasma level; T 1/2, half-life. 
Table 2 Major DOAC RCTs

\begin{tabular}{|l|l|l|}
\hline Drug and dose compared with warfarin & Clinical trial & Relative risk and 95\% IC \\
\hline Dabigatran 150-mg twice daily & RE-LY & $1.48(1.18-1.85)$ \\
\hline Dabigatran 110-mg twice daily & RE-LY & $1.08(0.85-1.38)$ \\
\hline Rivaroxaban 20-mg once daily & ROCKET-AF & $1.61(1.30-1.99)$ \\
\hline Apixaban 5-mg twice daily & ARISTOTELE & $0.89(0.70-1.15)$ \\
\hline Edoxaban 60-mg once daily & ENGAGE-TIMI 48 & $1.23(1.02-1,50)$ \\
\hline Edoxaban 30-mg once daily & ENGAGE-TIMI 48 & $0.67(0.53-0.83)$ \\
\hline
\end{tabular}

Abbreviations: $\mathrm{Cl}$, confidence interval; DOAC, direct oral anticoagulant; $\mathrm{RCT}$, randomized clinical trial.

of major GIB in patients given twice-daily doses of dabigatran $110 \mathrm{mg}$ did not increase. ${ }^{18}$

The ROCKET-AF trial compared patients taking rivaroxaban at a dose of $20 \mathrm{mg}$ daily (reduced to $15 \mathrm{mg}$ in cases of $\mathrm{CrCl}=30-50 \mathrm{~mL} / \mathrm{min}$ ) with those taking warfarin. Results indicated a greater prevalence of GIB, both major and minor, in those who were given rivaroxaban (HR: $1.42 ; 95 \% \mathrm{CI}$ : 1.22-1.66). ${ }^{19}$ A second analysis of the ROCKET-AF trial revealed a higher incidence of major GIB in patients aged 75 years or older: $2.81 / 100$ patient-years versus 1.41 in those aged below 75 years. ${ }^{20}$

The ARISTOTLE trial indicated that the rate of major bleeding with apixaban $20 \mathrm{mg}$ was $2.13 \%$ per year, as opposed to $3.09 \%$ per year in the group administered warfarin group (HR: 0.69; 95\% CI: $0.60-0.80$ ). Respective death rates due to any cause were 3.5 and 3.9\% (HR: 0.89; 95\% CI: 0.80-0.99). The possibility of major GIB associated with apixaban $20 \mathrm{mg}$ was similar to that of warfarin, with advanced age increasing the risk. In patients taking apixaban instead of warfarin, there was less of a risk of nonmajor bleeding including GIB (HR: 0.69; 95\% CI: 0.63-0.75). ${ }^{21}$

The ENGAGE AF-TIMI 48 trial studied the administration of edoxaban $60 \mathrm{mg}$ daily, edoxaban $30 \mathrm{mg}$ daily, and warfarin. The primary objectives of the study were the prevention of stroke or systemic embolism, wherein neither dose of edoxaban was inferior to warfarin. They were, however, linked to lower incidences of bleeding and death from cardiovascular causes. High doses of edoxaban were linked to a higher annualized rate of major GIB (1.51\%) compared with warfarin (1.23\%). However, the rate was lowest with low-dose edoxaban $(0.82 \%)^{22}$

The GIB risk of DOACs has been assessed in several systematic reviews and meta-analyses. A meta-analyses of phase-III RCTs showed that, compared with warfarin, rivaroxaban (risk ratio [RR]: 1.46; 95\% CI: 1.2-1.8), high dosage of edoxaban (RR: $1.22 ; 95 \% \mathrm{CI}: 1.01-1.47)$ and dabigatran (RR: 1.50; $95 \%$ CI: $1.20-1.88)$ significantly increased bleeding while null effect was detected with apixaban. ${ }^{23}$ Another meta-analysis pooled the results of 19 RCTs and was thus able to analyze 75,081 patients. It indicated a higher risk of GIB associated with DOACs in comparison with standard care (RR: $1.45 ; 95 \% \mathrm{CI}: 1.07-1.97) .{ }^{24}$ The study was a standard and high-quality meta-analysis, including all available RCTs. However, it was limited in two ways: first, both major and minor GIB were combined in establishing the outcome, and second, acute coronary syndrome studies were included in which controls were placebos and antiplatelet agents provided the basis for the administration of DOACs. Such an approach ran the risk of producing biased results and thus overestimating the risk of major GIB. An opposite result was reported in a 2015 study by Caldeira et al ${ }^{24,25}$ which used a precise definition of major GIB and pooled data by all indications. AMPLIFY-EXT and RE-SONATE, two trials that compared the effects of DOACs with placebos, were also included. The authors reported that there was no increased risk of major GIB associated with any of the individual DOACs. It should be noted that different controls (vitamin-K antagonists [VKAs], low molecular weight heparin [LMWH], aspirin, and placebo) were used to obtain the results for each individual DOAC. This approach, however, was restricted by a limited sample size in each subgroup, inevitably lessening the statistical power of the results.

A more recent meta-analysis included a total of 43 randomized trials, totaling 166,289 patients. They showed no difference between DOACs and conventional anticoagulants in the risk of major bleeding ( 1.5 vs. $1.3 \%$, respectively; HR: 0.98 ; $95 \% \mathrm{CI}$ : $0.80-1.21)$ or clinically relevant nonmajor bleeding (0.6 vs. 0.6\%, respectively; HR: 0.93; 95\% CI: 0.64-1.36). Dabigatran (2.0 vs. $1.4 \%$, respectively; HR: 1.27 ; $95 \% \mathrm{CI}: 1.04-1.55)$ and rivaroxaban (1.7 vs. $1.3 \%$, respectively; HR: 1.40 ; $95 \%$ CI: $1.15-1.70$ ) were linked with an increased likelihood of major GIB when compared with conventional anticoagulation. However, no such difference was observed for apixaban ( 0.6 vs. $0.7 \%$, respectively; HR: 0.81 ; $95 \%$ CI: $0.64-1.02$ ) or edoxaban (1.9 vs. $1.6 \%$, respectively; HR: $0.93 ; 95 \% \mathrm{CI}: 0.78-1.11) .{ }^{26}$ Therefore, the data indicate that an increased risk of GIB is associated with use of dabigatran and rivaroxaban compared with warfarin. However, it should be noted that the patients who participated in these trials had different numbers of comorbidities and risk factors, thus a cautious approach to this conclusion is advisable.

\section{Risk of Direct Oral Anticoagulants-Related Gastrointestinal Bleeding in Observational Studies}

Since the majority of RCTs adhered to stringent inclusion and exclusion criteria, so as to include only those patients with a relatively low risk of GIB, it may not be possible to generalize the results with respect to the general population. Furthermore, RCTs that separately investigated GIB did so only for major GIB. Thus, the risk of all GIB may have been underestimated. ${ }^{24}$ Studies performed by Graham et $\mathrm{al}^{27}$ and Hernandez et $\mathrm{al}^{28}$ utilized population-based data which revealed that dabigatran 
was associated with an increased rate of GIB relative to warfarin in patients with AF.

In a retrospective cohort study conducted by Hernandez et al, 1,302 patients taking dabigatran were compared with 8,102 patients taking warfarin. The study analyzed four subgroups of high-risk patients as follows: (1) those with chronic kidney disease, (2) African American patients, (3) patients aged 75 years or over, and (4) patients with seven or more concomitant comorbidities. Results indicated that all subgroups were subject to a greater risk of major GIB (HR: 1.85; 95\% CI: 1.64-2.07), highlighting African American patients and patients with chronic kidney disease as those most at risk. ${ }^{28}$

In a study by Abraham et al, ${ }^{29}$ rivaroxaban or dabigatran was not found to differ when compared with warfarin, with the exception of patients aged 75 years or over where both drugs were associated with an increased risk of GIB. However, other studies indicated that these drugs did not increase the risk. $^{30-32}$ In a recent propensity-matched cohort study in patients with $\mathrm{AF}$, results revealed that rivaroxaban, dabigatran, and apixaban were associated with increased, equivalent, and decreased risks, respectively, when compared with warfarin. ${ }^{33}$

Several observational studies have compared the risk of GIB with respect to different DOAC regimens. However, the results were limited due to several factors such as inconsistent definition of GIB, selective bias as a result of the observational nature of the study, lack of comparative study of all DOAC regimens, and it are often observed prescription of lower doses of DOACs and poor adherence among patients. Therefore, it becomes difficult to make a comparison between these results and those from meta-analysis.

The current data, when viewed together, indicate possible variability across DOACs with regard to GIB risk. They also highlight increased probability of GIB associated with rivaroxaban and dabigatran. However, such a link was not suggested for apixaban or edoxaban. This potential difference in GIB risk has yet to be explained in terms of biology. With respect to dabigatran, one possible cause could be the tartaric acid coating which exerts a direct caustic effect on the intestinal lumen. DOACs have also been shown to present some degree of intraluminal anticoagulant activity as a result of incomplete absorption across the GI mucosa. This is not the case for warfarin, which is almost completely absorbed and parenteral anticoagulants which are not taken orally. ${ }^{34}$ Such a hypothesis could be useful in explaining why dabigatran and rivaroxaban are associated with an increased risk when compared with conventional therapy. However, the difference among DOACs remains unclear. It should also be noted that, independent of GIB risk, all four studied agents were associated with a lower risk of intracranial bleed.

\section{Risk Factors for Gastrointestinal Bleeding with Anticoagulants}

Varying factors have been associated with a higher risk of major GIB in patients administered DOACs. Observational studies and RCTs both commonly investigate risk factors, particularly observational studies, due to the fact that highrisk patients are often left out by RCTs.
Several studies suggest that patients aged 75 years or over were at a greater risk of GIB associated with DOACs. ${ }^{29,30,35,36}$ Since elimination of DOACs is dependent on renal excretion, there is a higher likelihood of drug accumulation in patients with impaired renal function, and therefore a higher risk of bleeding. ${ }^{28}$ Patients with a past history of peptic ulcer disease or GIB are at a 2.3-fold increased risk of GIB. ${ }^{30}$ Another wellknown risk factor is concomitant antiplatelet therapy. ${ }^{30,37,38}$ Ethnicity was also established as a risk factor. This was observed in Chinese patients administered dabigatran where a higher incidence rate of GIB (4.2 per 100 person-years) was recorded. ${ }^{39}$ This is in contrast to the lower incidence rate observed in western populations (1.2-1.5 per 100 personyears in Denmark and 0.6 to 3.4 per 100 person-years in the United States). ${ }^{34,35}$ This difference could be explained by genetic factors, in particular, the $\mathrm{V}$ Leiden mutation which is extremely rare in Asians. ${ }^{40} \mathrm{~A}$ higher risk of GIB was also associated with liver cirrhosis (HR: 5.6; 95\% CI: 1.7-18.8) ${ }^{41}$ which increases the likelihood of both gastric or esophageal varices as a complication of portal hypertension and coagulation function abnormalities, and thus GIB.

In a recent study, chronic obstructive pulmonary disease (COPD) was associated with increased risk of GIB (HR: $4 ; 95 \% \mathrm{CI}$ : 1.4-11.2), although the precise mechanism behind this has yet to be explained. However, it is plausible that patients with COPD may have a long history of smoking which is a known risk factor for acute GIB. ${ }^{36,41}$ Analysis of data from 114,835 patients indicated that a higher risk of GIB was associated with concomitant use of oral anticoagulants (OACs) and other gastrotoxic drugs when compared with any of the drugs used alone: $\mathrm{OAC}+$ nonsteroidal anti-inflammatory drugs (NSAIDs; RR: 8.7; 95\% CI: 7.3- 10.4), OAC+ aspirin (RR: 6.9; 95\% CI: 5.9-8.2), and OAC + COX-2 inhibitors (coxibs; RR: 5.0; 95\% CI: 3.2-7.8). ${ }^{42}$ When OACs are used concurrently with other drugs, such as gemfibrozil, a higher risk of GIB was also observed (HR: $1.8 ; 95 \% \mathrm{CI}$ : $1.4-2.4){ }^{43}$ Anemia is often seen in patients with $A F$, and it could possibly be linked to a greater risk of new-onset $\mathrm{AF}^{44,45} \mathrm{VKAs}$ also put patients with anemia at a greater risk of bleeding. ${ }^{46-48}$ However, majority of randomized controlled trials of DOACs have not included patients with hemoglobin $<10 \mathrm{~g} / \mathrm{dL} .^{17,21,24,49}$ Furthermore, the current guidelines contain no specific recommendation regarding anticoagulant therapy in anemic patients with AF and hemoglobin $<10 \mathrm{~g} / \mathrm{dL}$ in current guidelines. ${ }^{2,50}$ A recent cohort study classified 8,356 patients with AF into two subgroups as follows: (1) patients with hemoglobin $\geq 10 \mathrm{~g} / \mathrm{dL}$ and (2) patients with hemoglobin $<10 \mathrm{~g} / \mathrm{dL}$. Compared with warfarin, DOACs were associated with a reduced risk of major bleeding or gastrointestinal tract bleeding in patients with $<10 \mathrm{~g} / \mathrm{dL}$ (HR: $0.43 ; 95 \%$ $\mathrm{CI}$ : 0.30-0.62). However, no such difference was observed in the incidence of ischemic stroke, systemic embolism, or death in anemic (HR: 0.79; 95\% CI: 0.53-1.17). ${ }^{51}$ Heart failure (HF) and AF often coexist. ${ }^{52}$ Patients with $\mathrm{HF}$ are at a higher risk of bleeding in comparison to non-HF controls. ${ }^{53}$ A history of HF also serves as a greater predictor of major bleeding than of thromboembolic risk. ${ }^{54}$ The efficacy and safety outcomes of DOACs compared with warfarin in patients with AFand HF have been examined by several studies. A meta-analysis conducted 
Table 3 Items of HAS-BLED ${ }^{56,57}$ bleeding risk score

\begin{tabular}{|l|l|l|}
\hline Clinical characteristics & Definition & Points \\
\hline Hypertension & Systolic blood pressure $>160 \mathrm{~mm} \mathrm{Hg}$ & 1 \\
\hline $\begin{array}{l}\text { Abnormal liver or } \\
\text { renal function }\end{array}$ & $\begin{array}{l}\text { Chronic liver disease (e.g., cirrhosis) or biochemical evidence of } \\
\text { significantly impaired liver function (e.g., bilirubin }>2 \text { times the ULN } \\
\text { plus one or more liver enzymes }>3 \text { times the ULN } \\
\text { Chronic dialysis, renal transplantation, or serum creatinine } \geq 200 \mu \mathrm{mol} / \mathrm{L}\end{array}$ & 1 or 2 \\
\hline Stroke & Previous history of stroke & 1 \\
\hline $\begin{array}{l}\text { Bleeding tendency } \\
\text { or predisposition }\end{array}$ & $\begin{array}{l}\text { Bleeding disorder or previous bleeding episode requiring } \\
\text { hospitalization or transfusion }\end{array}$ & 1 \\
\hline Labile INRs & $\begin{array}{l}\text { Labile INRs in patients taking warfarin (failure to maintain a } \\
\text { therapeutic range at least 60\% of the time) }\end{array}$ & 1 \\
\hline Elderly & Age $>65$ years & 1 \\
\hline Drugs & $\begin{array}{l}\text { Concomitant antiplatelet agents or NSAIDs excessive alcohol use } \\
(\geq 8 \text { units per week) }\end{array}$ & 1 or 2 \\
\hline
\end{tabular}

Abbreviations: INR, international normalized ratio; NSAID, nonsteroidal anti-inflammatory drugs; ULN, upper limit of normal.

recently observed no difference in $\mathrm{HF}$ and GIB (RR: 1.11 ; $95 \% \mathrm{CI}$ : $0.79-1.55) .{ }^{55}$

\section{Prevention of Gastrointestinal Bleeding Associated to Direct Oral Anticoagulants Treatment}

Before DOACs are prescribed, a strategy should be implemented to minimize risk. Should this fail, the identified risk factors should be considered so as to choose an appropriate prescription and dose.

Initially, the bleeding risk in patients with AF taking warfarin was derived by using the HAS-BLED (hypertension, abnormal liver/renal function, history of stroke, bleeding tendency, labile international normalized ratios [INRs], elderly aged $\geq 65$ years, and drug/alcohol use; - Table 3 ) score ${ }^{56,57}$ A score of $\geq 3$ indicates a high-risk patient, with a score of 3 , conferring 3.74 bleeding events per 100 patient years. It is important to recognize, however, that patients with a greater risk of thromboembolism usually present one or more of the comorbidities listed in the HAS-BLED criteria. They are therefore more predisposed to bleeding. DOACs should not be prescribed until patients have been screened for hepatic and kidney disease. In this way, a drug can be chosen which is compatible with the patient's comorbidities (-Tables 4 and 5). Drug interactions must be considered, as patients are commonly prescribed multiple drugs. This is especially important with drugs that are metabolized via the cytochrome P450 system and the P-gp efflux transporter. If possible, clarithromycin, fluconazole, itraconazole, amiodarone, cimetidine, rifampicin, carbamazepine, phenobarbital, and protease inhibitors should be not be used. ${ }^{58}$ This is also the case with combinations of any anticoagulant used with NSAIDs and coxibs. However, cases may arise where this is not possible. Should this occur, coxibs are preferred to traditional NSAIDs. ${ }^{59}$ A history of peptic ulcer may necessitate testing for Helicobacter pylori to prevent upper GIB. Proton pump inhibitor (PPI) treatment lowers the probability of upper GIB, ${ }^{60-62}$ but it is possible that the preventive effect of taking DOACs is not as great as that observed when PPIs are given in conjunction with gastrotoxic drugs such as NSAIDs or aspirin. ${ }^{63,64}$ It has been suggested that PPIs potentially interact with anticoagulants due to their shared liver metabolism via P450-cytocrome. However, this was ruled out in a multicenter case-control study. ${ }^{65}$ PPIs will not, however, prevent GIB from the lower GI tract, and further investigation is warranted regarding the potentially negative effect they have on intestinal microbiota. ${ }^{66}$

\section{Location of Gastrointestinal Bleeding: Upper versus Lower}

The lower GI tract is a common source of GIB in DOAC users. ${ }^{67}$ In a post hoc analysis of patients experiencing GIB during RELY, $47 \%$ of patients taking dabigatran 110 -mg twice daily and $47 \%$

Table 4 Use of DOACs according to renal function

\begin{tabular}{|c|c|c|c|c|}
\hline $\mathrm{CrCl}$ & Dabigatran & Rivaroxaban & Edoxaban & Apixaban \\
\hline$\geq 50 \mathrm{~mL} / \mathrm{min}$ & $2 \times 150 \mathrm{mg}$ & $20 \mathrm{mg}$ & $60 \mathrm{mg}$ & $2 \times 5 \mathrm{mg}$ or $2 \times 2.5 \mathrm{mg}^{\mathrm{a}}$ \\
\hline $50-30 \mathrm{~mL} / \mathrm{min}$ & $2 \times 150 \mathrm{mg}$ or $2 \times 110 \mathrm{mg}^{\mathrm{b}}$ & $15 \mathrm{mg}$ & $30 \mathrm{mg}$ & $2 \times 5 \mathrm{mg}$ or $2 \times 2.5 \mathrm{mg}^{\mathrm{a}}$ \\
\hline $30-15 \mathrm{~mL} / \mathrm{min}$ & No & $15 \mathrm{mg}$ & $30 \mathrm{mg}$ & $2 \times 2.5 \mathrm{mg}$ \\
\hline Dialysis & No & No & No & No \\
\hline
\end{tabular}

Abbreviations: $\mathrm{CrCl}$, creatinine clearance; DOAC, direct oral anticoagulant.

Note: $2 \times 2.5 \mathrm{mg}$ only if at least two out of the following three: age $\geq 80$ years, body weight $\leq 60 \mathrm{~kg}$, and/or creatinine $\geq 1.5 \mathrm{mg} / \mathrm{dL}$.

${ }^{\mathrm{a}} 2 \times 110 \mathrm{mg}$ in patients at high risk of bleeding.

${ }^{\mathrm{b}}$ Other dose reduction criteria may apply (weight $\leq 60 \mathrm{~kg}$, concomitant potent $\mathrm{P}$-Gb inhibitor therapy). 
Table 5 Use of DOACs in liver failure

\begin{tabular}{|l|l|l|l|l|}
\hline Child-Pugh category & Dabigatran & Rivaroxaban & Edoxaban & Apixaban \\
\hline A & No dose reduction & No dose reduction & No dose reduction & No dose reduction \\
\hline B & Use with caution & Do not use & Use with caution & Use with caution \\
\hline C & Do not use & Do not use & Do not use & Do not use \\
\hline
\end{tabular}

Abbreviation: DOAC, direct oral anticoagulant

of patients taking dabigatran 150 -mg twice daily were noted to have experienced lower GI bleeding. In contrast, only $25 \%$ of warfarin-associated GIB was from the lower tract. ${ }^{35}$ Dabigatran appears to increase the risk of lower GIB compared with warfarin. A retrospective study found a $30 \%$ increased risk of lower GIB with dabigatran (HR: 1.30; 95\% CI:1.04-1.62) ${ }^{68}$ In the ROCKET-AF trial, patients taking rivaroxaban had similar rates of upper and lower GIB as patients on warfarin: 48 and $47 \%$ of rivaroxaban and warfarin users, respectively, had upper GIB; 22 and 24\% had lower GIB, respectively; and 30 and 29\% had rectal bleeding, respectively. ${ }^{4}$ Similarly, in a postmarket retrospective cohort study of GIB in anticoagulated patients, $57 \%$ of patients taking rivaroxaban were found to have a lower GI source, as were $75 \%$ of the patients taking dabigatran. ${ }^{69}$. In ARISTOTLE, the most frequent specified site of major bleeding in patients taking apixaban was the digestive tract. Apixaban showed similar rates in terms of the location of bleeding; the event rate for upper versus lower GI bleeds in patients taking apixaban was 0.43 per 100 patient-years versus 0.25 per 100 patient-years. The event rate for upper versus lower GI bleeds in patients taking warfarin was 0.56 per 100 patient-years versus 0.24 per 100 patient-years. ${ }^{37}$ In the ENGAGE-AF-TIMI trial, the annualized rate of major bleeding events was $3.43 \%$ with warfarin versus $2.75 \%$ with high-dose edoxaban and $1.61 \%$ with low-dose edoxaban. The corresponding rates for upper GIB were $0.71,0.91$, and 0.56 with warfarin, high-dose edoxaban, and low-dose edoxaban, respectively; these rates were 30 to $50 \%$ higher than those reported for lower GIB $(0.52$, 0.62 , and 0.28 , respectively). ${ }^{22}$

\section{Management of Direct Oral Anticoagulants Therapy after a Gastrointestinal Bleeding Episode}

Patients taking DOACs who present with overt, nonmajor GIB require specific management consisting of drug cessation and endoscopic management. ${ }^{34,70,71}$ Should a non-life-threatening major bleeding event occur in patients with normal renal function, plasma levels of DOACs should normalize within 12 to 24 hours, although patients with renal insufficiency may require more time, particularly for dabigatran. ${ }^{34,50}$ In cases of severe bleeding and/or hemodynamic instability, options may include activated charcoal, hemodialysis/hemoperfusion, and reversing anticoagulation.

If the last dose of DOAC is given within 2 hours, activated charcoal can be used to reduce intestinal absorption of residual drug. This potential benefit must be weighed against subsequent impairment of endoscopic visualization. ${ }^{72}$ Should life-threatening GIB or renal failure occur, hemodialysis or hemoperfusion could also be considered for dabigatran. ${ }^{73}$ However, they should not be used for direct factor Xa inhibitors due to the fact they are highly protein bound. ${ }^{71}$ Nonspecific reversal agents include prothrombin complex concentrates (PCCs; either weight based three-factor or four-factor PCCs), activated (aPCCs) and recombinant factor VIla (rFVIIa), although they have been shown to increase the risk of thromboembolism. ${ }^{74,75}$ However, a recent study has demonstrated that four-factor PCCs possess a similar safety profile when compared with fresh frozen plasma in terms of thromboembolic events (around 7\%) and deaths. ${ }^{75}$ Due to their uncertain efficacy and potential risk of thromboembolism, these agents should only be administered in the following situations: lifethreatening GIB, ongoing bleeding despite standard measures, or delayed clearance of DOACs in patients with renal failure. ${ }^{70}$ Availability of PCC and aPCC, as well as the experience of the treatment center, generally determine which is used. This is particularly true in the case of aPCC which, since it induces a strong procoagulant effect, should only be administered by physicians with prior experience in its use. PCC and aPCC are preferred over rFVIIa due to the absence of outcome data and the latter's strong procoagulant effect. ${ }^{76,77}$ Antifibrinolytic agents (tranexamic acid) have been used to manage DOACrelated GIB, particularly in cases of severe bleeding where many factors of the coagulation cascade are often deficient, but the experience is still limited. ${ }^{70,78}$ Specific reversal agents have also been developed. Idarucizumab is a humanized monoclonal antibody fragment (Fab) against dabigatran which has been shown to be capable of rapidly reversing the anticoagulation activity of dabigatran within minutes in almost all patients. ${ }^{79}$ Andexanet alfa is a recombinant modified human factor Xa decoy protein which functions as a universal factor Xa reversal agent by binding to the factor Xa inhibitors. ${ }^{70}$ It has been shown to greatly reverse antifactor Xa activity and promote hemostasis in approximately $80 \%$ of patients with acute major bleeding. ${ }^{79}$ The severity of GIB and patients' hemodynamic status determines the timing of endoscopy. In situations of mild GIB, it is possible to defer endoscopic evaluation for 12 to 24 hours. $^{31,75,80}$ This delayed approach presents many advantages, such as increasing effectiveness of endoscopic intervention once the drug effects have worn off, increasing safety in a nonemergency setting, and improving endoscopic visualization due to attenuation/cessation of bleeding and better colonic cleansing. However, patients who either have GIB or hemodynamically unstable should undergo emergency endoscopy promptly after resuscitation. If endoscopic management fails, radiological and/or surgical interventions should be considered as a last resort. ${ }^{81}$ It is possible to restart nuisance or minor bleeding anticoagulation in the majority of cases, 
sometimes done by delaying or skipping a single dose. In other cases of bleeding, particularly those which are lifethreatening, careful reassessment of the risks and benefits or restarting anticoagulation is required. Specific data regarding restarting DOAC after GIB is lacking, thus there is an absence of randomized data on restarting medication post-GIB. The benefits and risks of resuming anticoagulant therapy following GIB were examined in a meta-analysis performed by Chai-Adisaksopha et $\mathrm{al}^{82}$ which involved the selection of three studies, including patients on warfarin for various reasons. Where warfarin was resumed (in $53 \%$ of patients), a substantial reduction in thromboembolic events (9.9 vs. $16.4 \%$, HR: 0.68 ; 95\% CI: $0.52-0.88$ ) and mortality (24.6 vs. $39.2 \%$, HR: 0.76 ; $95 \%$ CI: 0.66-0.88) was observed. However, it also revealed a numerically increased rate of recurrent GIB in cases where warfarin was resumed (10.1 vs. $5.5 \%, \mathrm{HR}$ : $1.20 ; 95 \% \mathrm{CI}$ : $0.97-1.48 ; p=0.10)$. The risk greatly increased where warfarin was resumed within 7 days as opposed to resuming later. In accordance with these findings, the European Society of Gastrointestinal Endoscopy (ESGE) guideline recommends that patients taking DOAC with moderate-to-severe GIB cease DOAC and resume 7 to 15 days after the GIB episode. Patients at an increased thrombotic risk, such as those with mechanical heart valve, cardiac assist device, or CHA2 DS2-VASc score $\geq 4$ may benefit from earlier (first week) resumption. ${ }^{83}$ However, many additional factors should also be considered. This is especially true in situations of severe and life-threatening bleeding without an obvious secondary or reversible/treatable cause, where the potential benefits may not be worth the risks of resuming anticoagulation. Should such a case arise, implantation of a left atrial appendage (LAA) occluder, or surgical LAA occlusion may represent a potential substitute for long-term anticoagulation. LAA occlusion appears to be a promising option for AF patients who are not candidates for long-term OAC. Recently increasing evidence of the utility of LAA occlusion in patients who are not candidates for long-term oral anticoagulation. Long-term data from two continued access registries, PROTECT-AF $^{84}$ and PREVAIL, ${ }^{85}$ to support LAA occlusion as a safe and effective long-term anticoagulation therapy. This new evidence led to class-IIb recommendation for left atrial appendage occlusion (LAAO) in nonvalvular atrial fibrillation patients not eligible for long-term OAC. PRAGUE-17 randomized controlled trial showed LAA occlusion is noninferior to $\mathrm{DOAC}^{86}$ Additionally, a lower dose or apixaban should be considered for patients with GIB while on DOAC ${ }^{2}$ (-Fig. 1).

\section{Patient after major gastrointestinal bleeding}

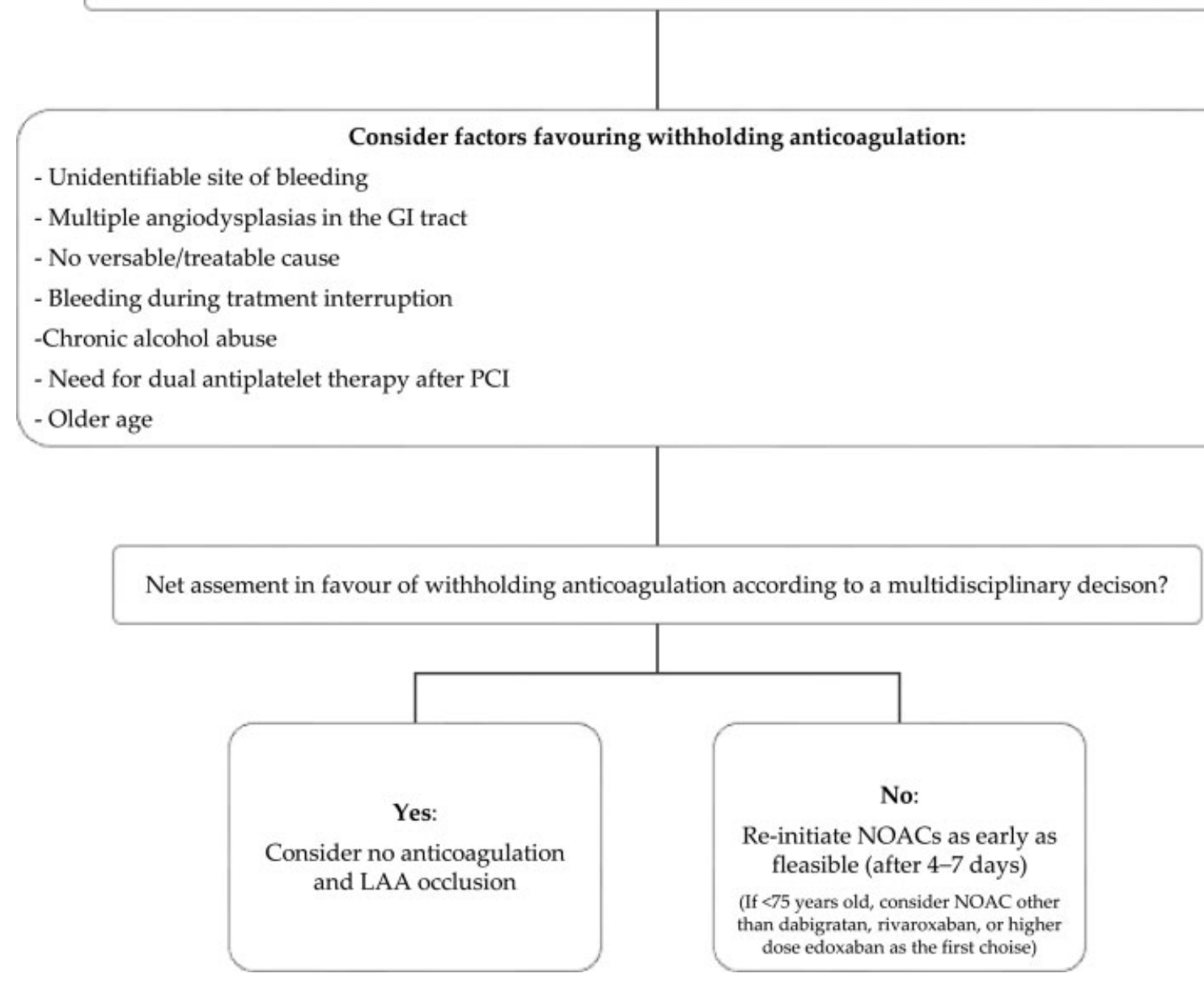

Fig. 1 Management of anticoagulant therapy after major gastrointestinal bleeding. GI, gastrointestinal; LAA, left atrial appendage; NOAC, nonvitamin $\mathrm{K}$ antagonist oral anticoagulants; $\mathrm{PCl}$, percutaneous coronary intervention. 


\section{Outcomes of major gastrointestinal bleeding (MGIB)}

Several studies have indicated that patient outcomes in cases of major bleeding into any organ while taking DOACs are no worse and might perhaps be more favorable than during VKA treatment. ${ }^{66}$ In RE-LY, the rate of life-threatening GIB was similar in patients treated with dabigatran 110-mg b.i.d. and warfarin. It increased, however, where dabigatran 150-mg b.i. d. was used $(p<0.004) .{ }^{87}$ Furthermore, patients on dabigatran who were experiencing major bleeding required fewer plasma transfusions but more packed red blood cell transfusions. They also spent less time in intensive care units and benefitted from an decreased mortality rate when compared with patients taking warfarin. ${ }^{88}$ Among patients with major GIB, ROCKET-AF found similar incidences of life-threatening bleeding, death, and transfusion of greater than 4 units of packed red blood cells in those taking rivaroxaban and warfarin. ${ }^{4}$ The ENGAGE-AF and ARISTOTELE studies also associated major GIB and DOACs with favorable outcomes in patients administered edoxaban and apixaban when compared with VKA. ${ }^{26,89}$ Data from the Dresden registry would also seem to support favorable outcomes for users of DOAC with major GIB, with a favorable rate of DOAC continuation compared with those taking VKA. ${ }^{90}$

\section{Patients' Quality of Life}

The extremely variable biological effects provoked by warfarin and their narrow therapeutic index make it a complicated drug to use. ${ }^{91,92}$ Patients who have undergone treatment with warfarin must therefore been seen more frequently at outpatient clinics to monitor their INR. Dietary restrictions must also be put in place to reduce vitamin-K intake, since it can adversely affect patients' HRQOL). ${ }^{93}$ While clinical studies have mainly attempted to evaluate the efficacy and safety of anticoagulant therapy, they have not focused so much on HRQOL. Period blood monitoring is not necessary to assess the efficacy of DOACs. They are also characterized by a wide therapeutic window and low inter- and intraindividual variability in dose-effect relation with fewer interactions between drugs. ${ }^{94}$ Several studies have examined how HRQOL is affected by OAC therapy. ${ }^{95}$ Corbi et al ${ }^{96}$ in their study recorded worse scores of HRQOL among women, the elderly, patients with less than 1 year of therapy, and those with an indication other than metallic prosthetic heart valve for OAC use. Warfarin was the most prescribed OAC in their study group, at $83.1 \%$. In another study conducted by Lancaster et al, ${ }^{97}$ no substantial difference between patients on warfarin and the control group were observed in terms of HRQOL until a bleeding episode had occurred. Their conclusion stated episodes of bleeding, such as GIB, led to patients experiencing a significant decrease in perceived health. A recent study indicated that DAOCs have comparable QOL, greater treatment satisfaction, reduced hospitalization, and a nonsignificant trend toward fewer bleeding episodes when compared with warfarin. ${ }^{89}$ Major GIB events in DOAC users are generally associated with favorable outcomes which is an important aspect that can influence HRQOL. ${ }^{90}$ In a European survey discontinuation related to bleeding was evident in only $4 \%$ of the patients. ${ }^{98}$
The preferences of AF patients toward anticoagulation shows that stroke risk reduction and limited bleeding risk are the most important attributes for an AF patient when deciding whether they are for or against a certain treatment. ${ }^{99}$

The Hospital Anxiety and Depression Scale (HADS) represents a reliable and valid tool in the assessment of depression and anxiety in patients and the general population. ${ }^{100}$ A recent study revealed a positive correlation between HADS scores and the annual number of hospital admissions, indicating that the warfarin group was more likely to suffer from depression and anxiety. When patients with effective INR levels were analyzed, HADS scores were seen to increase among those with ineffective INR levels. This can most likely be explained by the difficulties associated with gaining an effective INR level which have a detrimental effect on patients' emotional wellbeing and thus increase HADS scores. ${ }^{101}$ In conclusion, it is possible that DOACs improve symptoms of anxiety and depression in nonvalvular AF patients which would thus lead to a better HRQOL assessment and lower HADS scores in the DOAC group.

\section{Conclusion}

This article summarizes the current literature about GIB in patients on anticoagulant therapy. However, there is a lack of direct comparisons between DOACs. Current understanding is thus based on an unfortunately limited amount of evidence taken from observational studies and indirect comparisons in meta-analyses of RCTs. Rivaroxaban and dabigatran (particularly the 150-mg twice daily dose) are seemingly associated with a greater risk of GIB. This risk is also increased when edoxaban is administered, although it is dependent on the dose. With apixaban, the risk of GIB does not appear to increase in comparison to warfarin. Therefore, it is of the utmost importance that DOAC indications be reviewed and that a particular DOAC be prescribed on an individual basis. Physicians must also be aware of the risk factors for DOACrelated GIB and adopt the necessary preventive measures. Furthermore, higher levels of HRQOL were recorded among patients treated with DOACs as opposed to those treated with warfarin. These results may be linked to a lower rate of GIB events and fewer patients requiring hospitalization.

Conflict of Interest

None declared.

\section{References}

1 Lane DA, Wood K. A patient's guide to taking the non-vitamin $\mathrm{K}$ antagonist oral anticoagulants (NOACs) for atrial fibrillation. Circulation 2015;131(16):e412-e415

2 Hindricks G, Potpara T, Dagres N, et alESC Scientific Document Group. ESC guidelines for the diagnosis and management of atrial fibrillation developed in collaboration with the European Association of CardioThoracic Surgery (EACTS). Eur Heart J 2021;42(05):373-498

3 Barnes GD, Ageno W, Ansell J, Kaatz SSubcommittee on the Control of Anticoagulation of the International Society on Thrombosis and Haemostasis. Recommendation on the nomenclature for oral anticoagulants: communication from the SSC of the ISTH. J Thromb Haemost 2015;13(06):1154-1156 
4 Sherwood MW, Nessel CC, Hellkamp AS, et al. Gastrointestinal bleeding in patients with atrial fibrillation treated with rivaroxaban or warfarin: ROCKET AF trial. J Am Coll Cardiol 2015;66 (21):2271-2281

5 Agnelli G, Buller HR, Cohen A, et al; AMPLIFY Investigators. Oral apixaban for the treatment of acute venous thromboembolism. N Engl J Med 2013;369(09):799-808

6 Wang Y, Kong MC, Lee LH, Ng HJ, Ko Y. Knowledge, satisfaction, and concerns regarding warfarin therapy and their association with warfarin adherence and anticoagulation control. Thromb Res 2014;133(04):550-554

7 Keita I, Aubin-Auger I, Lalanne C, et al. Assessment of quality of life, satisfaction with anticoagulation therapy, and adherence to treatment in patients receiving long-course vitamin $\mathrm{K}$ antagonists or direct oral anticoagulants for venous thromboembolism. Patient Prefer Adherence 2017;11:1625-1634

8 Ware JE Jr, Sherbourne CD. The MOS 36-item short-form health survey (SF-36). I. Conceptual framework and item selection. Med Care 1992;30(06):473-483

9 The WHOQOL Group. Development of the World Health Organization WHOQOL-BREF quality of life assessment. Psychol Med 1998;28(03):551-558

10 Caruso S, Bandiera S, Cavallaro A, Cianci S, Vitale SG, Rugolo S. Quality of life and sexual changes after double transobturator tension-free approach to treat severe cystocele. Eur J Obstet Gynecol Reprod Biol 2010;151(01):106-109

11 Vitale SG, Caruso S, Rapisarda AMC, et al. Biocompatible porcine dermis graft to treat severe cystocele: impact on quality of life and sexuality. Arch Gynecol Obstet 2016;293(01):125-131

12 Vitale SG, Laganà AS, Noventa $M$, et al. Transvaginal bilateral sacrospinous fixation after second recurrence of vaginal vault prolapse: efficacy and impact on quality of life and sexuality. BioMed Res Int 2018;2018:5727165

13 Caruso S, Cianci S, Vitale SG, Fava V, Cutello S, Cianci A. Sexual function and quality of life of women adopting the levonorgestrel-releasing intrauterine system (LNG-IUS $13.5 \mathrm{mg}$ ) after abortion for unintended pregnancy. Eur J Contracept Reprod Health Care 2018;23(01):24-31

14 Hankey GJ, Eikelboom JW. Dabigatran etexilate: a new oral thrombin inhibitor. Circulation 2011;123(13):1436-1450

15 Salem J-E, Sabouret P, Funck-Brentano C, Hulot J-S. Pharmacology and mechanisms of action of new oral anticoagulants. Fundam Clin Pharmacol 2015;29(01):10-20. Doi: 10.1111/fcp.12091

16 Ruff CT, Giugliano RP, Braunwald E, et al. Association between edoxaban dose, concentration, anti-Factor Xa activity, and outcomes: an analysis of data from the randomised, double-blind ENGAGE AF-TIMI 48 trial. Lancet 2015;385(9984):2288-2295

17 Connolly SJ, Ezekowitz MD, Yusuf S, et al; RE-LY Steering Committee and Investigators. Dabigatran versus warfarin in patients with atrial fibrillation. N Engl J Med 2009;361(12): 1139-1151

18 Connolly SJ, Wallentin L, Ezekowitz MD, et al. The long-term multicenter observational study of dabigatran treatment in patients with atrial fibrillation (RELY-ABLE) study. Circulation 2013;128(03):237-243

19 Patel MR, Mahaffey KW, Garg J, et al; ROCKET AF Investigators. Rivaroxaban versus warfarin in nonvalvular atrial fibrillation. N Engl J Med 2011;365(10):883-891

20 Halperin JL, Hankey GJ, Wojdyla DM, et al; ROCKET AF Steering Committee and Investigators. Efficacy and safety of rivaroxaban compared with warfarin among elderly patients with nonvalvular atrial fibrillation in the Rivaroxaban Once Daily, Oral, Direct Factor Xa Inhibition Compared With Vitamin K Antagonism for Prevention of Stroke and Embolism Trial in Atrial Fibrillation (ROCKET AF). Circulation 2014;130(02):138-146

21 Granger CB, Alexander JH, McMurray JJV, et al; ARISTOTLE Committees and Investigators. Apixaban versus warfarin in patients with atrial fibrillation. N Engl J Med 2011;365(11): 981-992

22 Giugliano RP, Ruff CT, Braunwald E, et al; ENGAGE AF-TIMI 48 Investigators. Edoxaban versus warfarin in patients with atrial fibrillation. N Engl J Med 2013;369(22):2093-2104

23 Loffredo L, Perri L, Violi F. Impact of new oral anticoagulants on gastrointestinal bleeding in atrial fibrillation: a meta-analysis of interventional trials. Dig Liver Dis 2015;47(05):429-431

24 Holster IL, Valkhoff VE, Kuipers EJ, Tjwa ETTL. New oral anticoagulants increase risk for gastrointestinal bleeding: a systematic review and meta-analysis. Gastroenterology 2013;145(01): 105-112.e15

25 Caldeira D, Barra M, Ferreira A, et al. Systematic review with meta-analysis: the risk of major gastrointestinal bleeding with non-vitamin K antagonist oral anticoagulants. Aliment Pharmacol Ther 2015;42(11, 12):1239-1249

26 Miller CS, Dorreen A, Martel M, Huynh T, Barkun AN. Risk of gastrointestinal bleeding in patients taking non-vitamin $\mathrm{K}$ antagonist oral anticoagulants: a systematic review and metaanalysis. Clin Gastroenterol Hepatol 2017;15(11):1674-1683.e3

27 Graham DJ, Reichman ME, Wernecke M, et al. Stroke, bleeding, and mortality risks in elderly medicare beneficiaries treated with dabigatran or rivaroxaban for nonvalvular atrial fibrillation. JAMA Intern Med 2016;176(11):1662-1671

28 Hernandez I, Baik SH, Piñera A, Zhang Y. Risk of bleeding with dabigatran in atrial fibrillation. JAMA Intern Med 2015;175(01): $18-24$

29 Abraham NS, Singh S, Alexander GC, et al. Comparative risk of gastrointestinal bleeding with dabigatran, rivaroxaban, and warfarin: population based cohort study. BMJ 2015;350:h1857

30 Chang H-Y, Zhou M, Tang W, Alexander GC, Singh S. Risk of gastrointestinal bleeding associated with oral anticoagulants: population based retrospective cohort study. BMJ 2015;350: h1585

31 Larsen TB, Rasmussen LH, Skjøth F, et al. Efficacy and safety of dabigatran etexilate and warfarin in "real-world" patients with atrial fibrillation: a prospective nationwide cohort study. J Am Coll Cardiol 2013;61(22):2264-2273

32 Southworth MR, Reichman ME, Unger EF. Dabigatran and postmarketing reports of bleeding. N Engl J Med 2013;368(14): $1272-1274$

33 Yao X, Abraham NS, Sangaralingham LR, et al. Effectiveness and safety of dabigatran, rivaroxaban, and apixaban versus warfarin in nonvalvular atrial fibrillation. J Am Heart Assoc 2016;5(06): e003725

34 Desai J, Kolb JM, Weitz JI, Aisenberg J. Gastrointestinal bleeding with the new oral anticoagulants-defining the issues and the management strategies. Thromb Haemost 2013;110(02):205-212

35 Eikelboom JW, Wallentin L, Connolly SJ, et al. Risk of bleeding with 2 doses of dabigatran compared with warfarin in older and younger patients with atrial fibrillation: an analysis of the randomized evaluation of long-term anticoagulant therapy (RE-LY) trial. Circulation 2011;123(21):2363-2372

36 Laursen SB, Hansen JM, Hallas J, Schaffalitzky de Muckadell OB. The excess long-term mortality in peptic ulcer bleeding is explained by nonspecific comorbidity. Scand J Gastroenterol 2015;50(02):145-152

37 Hylek EM, Held C, Alexander JH, et al. Major bleeding in patients with atrial fibrillation receiving apixaban or warfarin: The ARISTOTLE Trial (Apixaban for Reduction in Stroke and Other Thromboembolic Events in Atrial Fibrillation): predictors, characteristics, and clinical outcomes. J Am Coll Cardiol 2014;63(20): 2141-2147

38 Dans AL, Connolly SJ, Wallentin L, et al. Concomitant use of antiplatelet therapy with dabigatran or warfarin in the Randomized Evaluation of Long-Term Anticoagulation Therapy (RE-LY) trial. Circulation 2013;127(05):634-640 
39 Chan EW, Lau WCY, Leung WK, et al. Prevention of dabigatranrelated gastrointestinal bleeding with gastroprotective agents: a population-based study. Gastroenterology 2015;149(03): 586-95.e3

40 Hori M, Connolly SJ, Zhu J, et al; RE-LY Investigators. Dabigatran versus warfarin: effects on ischemic and hemorrhagic strokes and bleeding in Asians and non-Asians with atrial fibrillation. Stroke 2013;44(07):1891-1896

41 Shimomura A, Nagata N, Shimbo T, et al. New predictive model for acute gastrointestinal bleeding in patients taking oral anticoagulants: A cohort study. J Gastroenterol Hepatol 2018;33 (01):164-171

42 Masclee GMC, Valkhoff VE, Coloma PM, et al. Risk of upper gastrointestinal bleeding from different drug combinations. Gastroenterology 2014;147(04):784-792.e9, quiz e13-e14

43 Leonard CE, Brensinger CM, Bilker WB, et al. Gastrointestinal bleeding and intracranial hemorrhage in concomitant users of warfarin and antihyperlipidemics. Int J Cardiol 2017; 228:761-770

44 Westenbrink BD, Alings M, Granger CB, et al. Anemia is associated with bleeding and mortality, but not stroke, in patients with atrial fibrillation: Insights from the Apixaban for Reduction in Stroke and Other Thromboembolic Events in Atrial Fibrillation (ARISTOTLE) trial. Am Heart J 2017;185:140-149

$45 \mathrm{Hu}$ W-S, Sung F-C, Lin C-L. Aplastic anemia and risk of incident atrial fibrillation- a nationwide cohort study. Circ J 2018;82(05): 1279-1285

46 Gage BF, Yan Y, Milligan PE, et al. Clinical classification schemes for predicting hemorrhage: results from the National Registry of Atrial Fibrillation (NRAF). Am Heart J 2006;151(03):713-719

47 Fang MC, Go AS, Chang Y, et al. A new risk scheme to predict warfarin-associated hemorrhage: The ATRIA (Anticoagulation and Risk Factors in Atrial Fibrillation) Study. J Am Coll Cardiol 2011;58(04):395-401

48 O'Brien EC, Simon DN, Thomas LE, et al. The ORBIT bleeding score: a simple bedside score to assess bleeding risk in atrial fibrillation. Eur Heart J 2015;36(46):3258-3264

49 Connolly SJ, Eikelboom J, Joyner C, et al; AVERROES Steering Committee and Investigators. Apixaban in patients with atrial fibrillation. N Engl J Med 2011;364(09):806-817

50 Steffel J, Verhamme P, Potpara TS, et al; ESC Scientific Document Group. The 2018 European Heart Rhythm Association Practical Guide on the use of non-vitamin K antagonist oral anticoagulants in patients with atrial fibrillation. Eur Heart J 2018;39(16): 1330-1393

51 Wang C-L, Wu VC-C, Huang Y-T, et al. Safety and effectiveness of non-vitamin $\mathrm{K}$ antagonist oral anticoagulants for stroke prevention in patients with atrial fibrillation and anemia: a retrospective cohort study. J Am Heart Assoc 2019;8(09):e012029

52 Boos CJ, Brown L. Anticoagulation in atrial fibrillation and chronic heart failure: the risk and drug of choice. Curr Opin Cardiol 2016;31(02):229-234

53 DiMarco JP, Flaker G, Waldo AL, et al; AFFIRM Investigators. Factors affecting bleeding risk during anticoagulant therapy in patients with atrial fibrillation: observations from the Atrial Fibrillation Follow-up Investigation of Rhythm Management (AFFIRM) study. Am Heart J 2005;149(04):650-656

54 Friberg L, Rosenqvist M, Lip GYH. Evaluation of risk stratification schemes for ischaemic stroke and bleeding in 182678 patients with atrial fibrillation: the Swedish Atrial Fibrillation cohort study. Eur Heart J 2012;33(12):1500-1510

55 Chen F, Zhou Y, Wan Q, Yu P, Ma J, Hu J. Effect of non-vitamin K antagonist oral anticoagulants versus warfarin in heart failure patients with atrial fibrillation. Heart Fail Rev 2020 (e-pub ahead of print). Doi: 10.1007/s10741-020-09946-8

56 Pisters R, Lane DA, Nieuwlaat R, de Vos CB, Crijns HJGM, Lip GYH. A novel user-friendly score (HAS-BLED) to assess 1-year risk of major bleeding in patients with atrial fibrillation: the Euro Heart Survey. Chest 2010;138(05):1093-1100

57 Lip GYH, Frison L, Halperin JL, Lane DA. Comparative validation of a novel risk score for predicting bleeding risk in anticoagulated patients with atrial fibrillation: the HAS-BLED (Hypertension, Abnormal Renal/Liver Function, Stroke, Bleeding History or Predisposition, Labile INR, Elderly, Drugs/Alcohol Concomitantly) score. J Am Coll Cardiol 2011;57(02):173-180

58 Davidson BL, Verheijen S, Lensing AWA, et al. Bleeding risk of patients with acute venous thromboembolism taking nonsteroidal anti-inflammatory drugs or aspirin. JAMA Intern Med 2014; 174(06):947-953

59 Lanas A, Benito P, Alonso J, et al; Spanish Society of Rhematology Spanish Association of Gastroenterology Spanish Society of Cardiology. Safe prescription recommendations for non steroidal anti-inflammatory drugs: consensus document ellaborated by nominated experts of three scientific associations (SER-SECAEG). Reumatol Clin 2014;10(02):68-84

60 Abraham NS. New clinical paradigms for treating and preventing antiplatelet gastrointestinal bleeding. Curr Opin Gastroenterol 2017;33(06):467-472

61 Lauffenburger JC, Rhoney DH, Farley JF, Gehi AK, Fang G. Predictors of gastrointestinal bleeding among patients with atrial fibrillation after initiating dabigatran therapy. Pharmacotherapy 2015;35(06):560-568

62 Steinberg BA, Kim S, Piccini JP, et al; ORBIT-AF Investigators and Patients. Use and associated risks of concomitant aspirin therapy with oral anticoagulation in patients with atrial fibrillation: insights from the Outcomes Registry for Better Informed Treatment of Atrial Fibrillation (ORBIT-AF) Registry. Circulation 2013; 128(07):721-728

63 Staudacher DL, Kaiser M, Hehrlein C, Bode C, Ahrens I. Triple antithrombotic therapy after percutaneous coronary intervention $(\mathrm{PCI})$ in patients with indication for oral anticoagulation: data from a single center registry. PLoS One 2015;10(10): e0140101

64 Lanas A, García-Rodríguez LA, Arroyo MT, et al; Investigators of the Asociación Española de Gastroenterología (AEG) Effect of antisecretory drugs and nitrates on the risk of ulcer bleeding associated with nonsteroidal anti-inflammatory drugs, antiplatelet agents, and anticoagulants. Am J Gastroenterol 2007; 102(03):507-515

65 Nagata N, Niikura R, Yamada A, et al. Acute middle gastrointestinal bleeding risk associated with NSAIDs, antithrombotic drugs, and PPIs: a multicenter case-control study. PLoS One 2016;11(03):e0151332

66 Lué A, Lanas A. Protons pump inhibitor treatment and lower gastrointestinal bleeding: Balancing risks and benefits. World J Gastroenterol 2016;22(48):10477-10481

67 Lanas-Gimeno A, Lanas A. Risk of gastrointestinal bleeding during anticoagulant treatment. Expert Opin Drug Saf 2017;16 (06):673-685

68 Sengupta N, Tapper EB, Patwardhan VR, et al. Risk factors for adverse outcomes in patients hospitalized with lower gastrointestinal bleeding. Mayo Clin Proc 2015;90(08):1021-1029

69 Sherid M, Sifuentes H, Sulaiman S, et al. Risk of gastrointestinal bleeding with dabigatran: a head-to-head comparative study with rivaroxaban. Digestion 2014;90(02):137-146

70 Weitz JI, Pollack CV Jr. Practical management of bleeding in patients receiving non-vitamin $\mathrm{K}$ antagonist oral anticoagulants. Thromb Haemost 2015;114(06):1113-1126

71 Inohara $\mathrm{T}$, Xian Y, Liang L, et al. Association of intracerebral hemorrhage among patients taking non-vitamin $\mathrm{K}$ antagonist vs vitamin $\mathrm{K}$ antagonist oral anticoagulants with in-hospital mortality. JAMA 2018;319(05):463-473

72 van Ryn J, Stangier J, Haertter S, et al. Dabigatran etexilate-a novel, reversible, oral direct thrombin inhibitor: interpretation 
of coagulation assays and reversal of anticoagulant activity. Thromb Haemost 2010;103(06):1116-1127

73 Khadzhynov D, Wagner F, Formella S, et al. Effective elimination of dabigatran by haemodialysis. A phase I single-centre study in patients with end-stage renal disease. Thromb Haemost 2013; 109(04):596-605

74 Dusel CH, Grundmann C, Eich S, Seitz R, König H. Identification of prothrombin as a major thrombogenic agent in prothrombin complex concentrates. Blood Coagul Fibrinolysis 2004;15(05):405-411

75 Milling TJ Jr., Refaai MA, Sarode R, et al. Safety of a four-factor prothrombin complex concentrate versus plasma for vitamin $\mathrm{k}$ antagonist reversal: an integrated analysis of two phase IIIb clinical trials. Acad Emerg Med 2016;23(04):466-475

76 Tomaselli GF, Mahaffey KW, Cuker A, et al. 2017 ACC expert consensus decision pathway on management of bleeding in patients on oral anticoagulants: a report of the American College of Cardiology Task Force on expert consensus decision pathways. J Am Coll Cardiol 2017;70(24):3042-3067

77 Warkentin TE, Margetts P, Connolly SJ, Lamy A, Ricci C, Eikelboom JW. Recombinant factor VIIa (rFVIIa) and hemodialysis to manage massive dabigatran-associated postcardiac surgery bleeding. Blood 2012;119(09):2172-2174

78 Masotti L, Lorenzini G, Seravalle C, et al. Management of new oral anticoagulants related life threatening or major bleedings in real life: a brief report. J Thromb Thrombolysis 2015;39(04):427-433

79 Pollack CV Jr., Reilly PA, van Ryn J, et al. Idarucizumab for dabigatran reversal - full cohort analysis. N Engl J Med 2017; 377(05):431-441

80 Connolly SJ, Milling TJ Jr, Eikelboom JW, et al; ANNEXA-4 Investigators. Andexanet alfa for acute major bleeding associated with factor Xa inhibitors. N Engl J Med 2016;375(12):1131-1141

81 Hwang JH, Fisher DA, Ben-Menachem T, et al; Standards of Practice Committee of the American Society for Gastrointestinal Endoscopy. The role of endoscopy in the management of acute non-variceal upper GI bleeding. Gastrointest Endosc 2012;75 (06):1132-1138

82 Chai-Adisaksopha C, Hillis C, Monreal M, Witt DM, Crowther M. Thromboembolic events, recurrent bleeding and mortality after resuming anticoagulant following gastrointestinal bleeding. A meta-analysis. Thromb Haemost 2015;114(04):819-825

83 Gralnek IM, Dumonceau J-M, Kuipers EJ, et al. Diagnosis and management of nonvariceal upper gastrointestinal hemorrhage: European Society of Gastrointestinal Endoscopy (ESGE) Guideline. Endoscopy 2015;47(10):a1-a46

84 Reddy VY, Sievert H, Halperin J, et al; PROTECT AF Steering Committee and Investigators. Percutaneous left atrial appendage closure vs warfarin for atrial fibrillation: a randomized clinical trial. JAMA 2014;312(19):1988-1998

85 Holmes DR Jr., Kar S, Price MJ, et al. Prospective randomized evaluation of the Watchman Left Atrial Appendage Closure device in patients with atrial fibrillation versus long-term warfarin therapy: the PREVAIL trial. J Am Coll Cardiol 2014;64(01):1-12

86 Osmancik P, Herman D, Neuzil P, et al; PRAGUE-17 Trial Investigators. Left atrial appendage closure versus direct oral anti- coagulants in high-risk patients with atrial fibrillation. J Am Coll Cardiol 2020;75(25):3122-3135

87 Majeed A, Hwang H-G, Connolly SJ, et al. Management and outcomes of major bleeding during treatment with dabigatran or warfarin. Circulation 2013;128(21):2325-2332

88 Werth S, Breslin T, NiAinle F, Beyer-Westendorf J. Bleeding risk, management and outcome in patients receiving non-VKA oral anticoagulants (NOACs). Am J Cardiovasc Drugs 2015;15(04): 235-242

$89 \mathrm{Ng}$ DL-C, Gan G-G, Chai C-S, et al. Comparing quality of life and treatment satisfaction between patients on warfarin and direct oral anticoagulants: a cross-sectional study. Patient Prefer Adherence 2019;13:1363-1373

90 Beyer-Westendorf J, Förster K, Pannach S, et al. Rates, management, and outcome of rivaroxaban bleeding in daily care: results from the Dresden NOAC registry. Blood 2014;124(06):955-962

91 Kepez A, Erdoğan O. Anticoagulation for non-valvular atrial fibrillation: new anticoagulant agents. Anadolu Kardiyol Derg 2013;13(04):379-384

92 Ansell J, Hirsh J, Poller L, Bussey H, Jacobson A, Hylek E. The pharmacology and management of the vitamin $\mathrm{K}$ antagonists: the Seventh ACCP Conference on Antithrombotic and Thrombolytic Therapy. Chest 2004;126(3, suppl):204S-233S

93 Casais P, Meschengieser SS, Sanchez-Luceros A, Lazzari MA. Patients' perceptions regarding oral anticoagulation therapy and its effect on quality of life. Curr Med Res Opin 2005;21 (07):1085-1090

94 Mani H, Lindhoff-Last E. New oral anticoagulants in patients with nonvalvular atrial fibrillation: a review of pharmacokinetics, safety, efficacy, quality of life, and cost effectiveness. Drug Des Devel Ther 2014;8:789-798

95 Ynsaurriaga FA, Peinado RP, Ormaetxe Merodio JM. Atrial fibrillation and quality of life related to disease and treatment: focus on anticoagulation. Future Cardiol 2014;10(03):381-393

96 Corbi ISA, Dantas RAS, Pelegrino FM, Carvalho AR. Health related quality of life of patients undergoing oral anticoagulation therapy. Rev Lat Am Enfermagem 2011;19(04):865-873

97 Lancaster TR, Singer DE, Sheehan MA, et al; Boston Area Anticoagulation Trial for Atrial Fibrillation Investigators. The impact of long-term warfarin therapy on quality of life. Evidence from a randomized trial. Arch Intern Med 1991;151(10):1944-1949

98 Giardini A, Martin MT, Cahir C, et al. Toward appropriate criteria in medication adherence assessment in older persons: position Paper. Aging Clin Exp Res 2016;28(03):371-381

99 Wilke T, Bauer S, Mueller S, Kohlmann T, Bauersachs R. Patient preferences for oral anticoagulation therapy in atrial fibrillation: a systematic literature review. Patient 2017;10(01):17-37

100 Bjelland I, Dahl AA, Haug TT, Neckelmann D. The validity of the Hospital Anxiety and Depression Scale. An updated literature review. J Psychosom Res 2002;52(02):69-77

101 Balcı KG, Balcı MM, Canpolat U, et al. Comparison of healthrelated quality of life among patients using novel oral anticoagulants or warfarin for non-valvular atrial fibrillation. Anatol J Cardiol 2016;16(07):474-481 